\title{
Field Measurements and Flow Modeling of Overbank Flows in River Severn, U.K.
}

\author{
K. Babaeyan-Koopaei ${ }^{1 *}$, D. A. Ervine ${ }^{2}$ and G. Pender ${ }^{3}$ \\ ${ }^{1}$ Carl Bro Group, Lynedoch Place, Glasgow G3 6AB, UK \\ ${ }^{2}$ Department of Civil Engineering, University of Glasgow, Glasgow G12 8LT, UK \\ ${ }^{3}$ School of the Built Environment, Heriot-Watt Univ., Edinburgh EH14 4AS, UK
}

\begin{abstract}
Field measurements of velocity and turbulence have been carried out in a study reach of the River Severn (U.K.) during overbank flows. Directional current (DCM) and acoustic Doppler Velocity (ADV) meters have been used for the field measurements of velocity and turbulence particularly in the interface region between main channel and floodplain. The values of local shear velocity and roughness length for the reach under study were calculated using measured velocity data. The distributions of turbulent intensities, and the Reynolds stresses are also presented. A two-dimensional depth averaged numerical model is used to investigate how accurately the field measurements are reproduced. A fully $3 \mathrm{D}$ model of the river reach is also constructed using CFX and the results are presented.
\end{abstract}

Keywords: velocity, turbulence, field measurements, overbankflow, flow modeling

\section{Introduction}

This paper is the result of a collaborative research study on river flooding that has been carried out between Glasgow, Lancaster, Southampton, and Heriot-Watt Universities. It focuses on the results relating to the field measurements and the flow modeling that have been carried out in the River Severn.

Field measurements of velocity and turbulence have been carried out in a study reach on the River Severn near Shrewsbury in Shropshire, U.K. (Figure 1). The study reach of interest to the current work is located $20 \mathrm{~km}$ east of Shrewsbury. A single meander about $600 \mathrm{~m}$ long (Figure 2), located south of Llandrinio, near Lower Farm was used for this study. At this location the main channel is about $30 \mathrm{~m}$ wide, between 6.0 and $7.0 \mathrm{~m}$ deep with respect to the right floodplain but more than $9.0 \mathrm{~m}$ with respect to the higher left floodplain. The right floodplain is $180 \mathrm{~m}$ wide and $120 \mathrm{~m}$ long, and is bunded by an earth embankment to the south. The upstream right flood plain of the study reach has been artificially lowered to extract material for the construction of the embankments, and is, as a result, fairly flat. On the other hand the downstream left flood plain is rarely flooded and only a very extreme flood would be required for it to be inundated. The geometry of the study reach is comparable to an asymmetric meandering compound channel. Figure 1 shows the study reach.

\footnotetext{
* Corresponding author: k.b.koopaei@carlbro.com
}

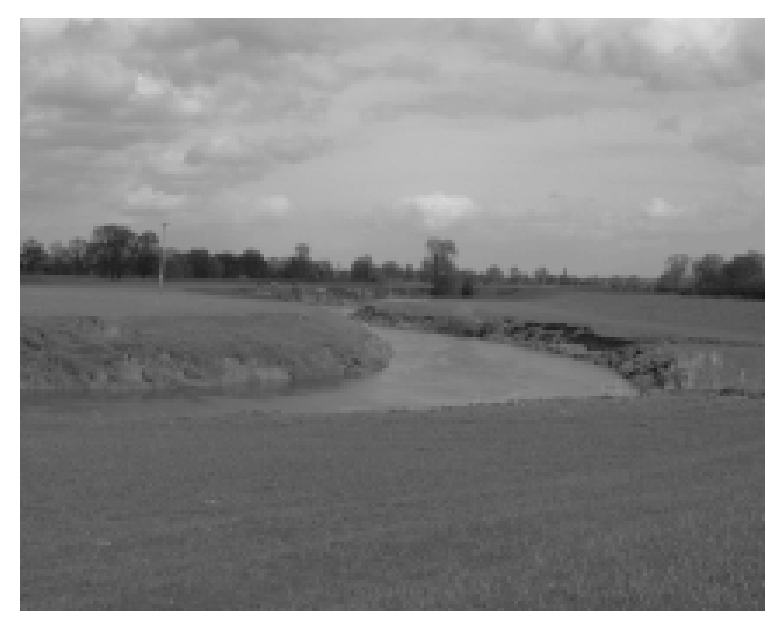

Figure 1. The study reach at River Severn.

\section{Field Set-up for Velocity and Turbulence Measurements}

Velocity measurements for the cross-sections 1 to 5 were carried out using a cable-supported Directional Current Meter (DCM) deployed from a boat. The DCM was lowered from the boat to different depths within the flow and the point velocities were measured to an accuracy of $0.1 \mathrm{~m} / \mathrm{s}$. The output time series (velocity and direction of the horizontal component of 3D velocity) from the current meter were recorded using a portable PC. A full width velocity survey was carried out to establish flow discharge. 
calculated by:

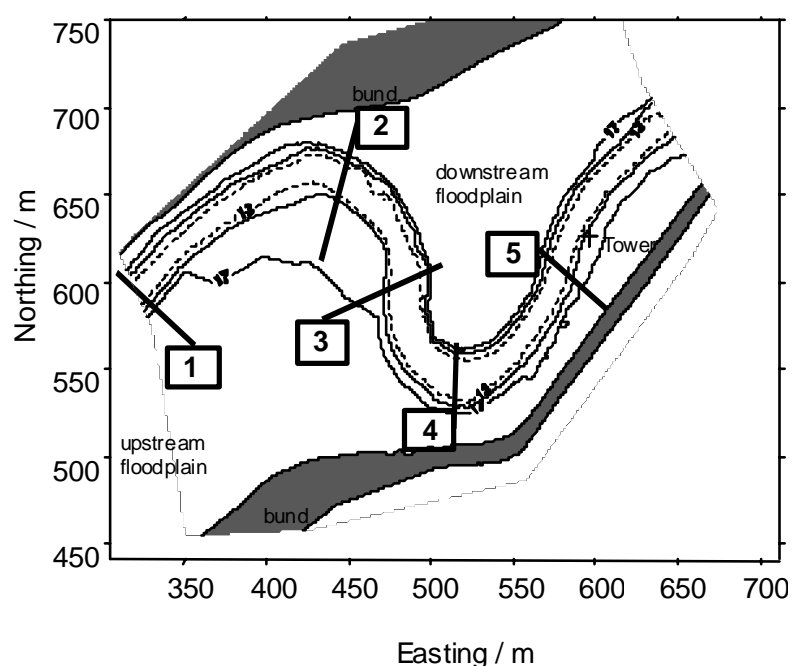

Figure 2. Velocity measurements at different crosssections in River Severn (UK).

Turbulence characteristics of the flow were measured using a downward-looking three-dimensional computer operated Acoustic Doppler Velocity meter (ADV), from a scaffolding tower over the $8 \mathrm{~m}$ width, downstream of section 5, as shown in Figure 2. The channel cross-section at the tower is shown in Figure 3. The ADV system consisted of a signal conditioning module, a probe with an acoustic transmitter and three acoustic receivers, and an ADV processor. The sampling volume is approximately $0.25 \mathrm{~cm}^{3}$, which is $10 \mathrm{~cm}$ below the transmitting transducer. This enables measurements to be taken without interfering with the flow. The ADV sampling rate was $25 \mathrm{~Hz}$ and collected instantaneous local flow velocity data in the streamwise, vertical, and transverse directions. Field ADV probes were used with a velocity range of \pm 0.03 to \pm 2.5 $\mathrm{m} / \mathrm{s}$. The total sampling time was made according to a criterion of Nezu and Nakagawa (1993) with a total sampling time more than three minutes to ensure that an adequate number of turbulent bursts and structures were recorded. The noise effects on measurements of turbulence were considered using Nikora and Goring (1998) technique to reduce the Doppler noise influence. The probe orientation can also affect the Reynolds stress measurements and the measured pattern of secondary currents. Shiono and Knight (1991) stated that a $1^{\circ}$ error in frame rotation would add errors of between $1 \%$ and $4 \%$ to the measurements; therefore the probes were accordingly aligned to minimize the probe orientation errors.

\section{Shear Velocity and Roughness Length}

Bed shear velocity has been calculated using the following methods.

(a) The reach averaged bed-shear velocity is often

$$
\bar{U}_{*}=\sqrt{g R S_{f}}
$$

where $\mathrm{g}=$ gravitational acceleration; $S_{\mathrm{f}}=$ energy slope; and $R=$ hydraulic radius (reach-averaged values).

(b) Shear velocity can also be computed by assuming an equation for the vertical profile of velocity. Reliable formulae for estimating the vertical distribution of longitudinal time-averaged velocities are still a problem in river mechanics, even for two-dimensional flows (Nikora and Smart, 1997). According to Nezu and Nakagawa (1993) velocity profiles in open channel flows can be reproduced accurately using the log-wake law.

$\frac{u}{U_{*}}=\frac{1}{\kappa} \ln \left(\frac{z}{Z_{o}}\right)+W(z / H)$

where $Z_{\mathrm{o}}$ describes the roughness length, $\mathrm{u}$ is the time-averaged streamwise velocity at distance $z$ above the bed, and $\mathrm{W}(\mathrm{z} / \mathrm{H})$ is the wake function. The use of a wake function is necessary in order to describe the velocity in the outer region of the flow but for the inner, logarithmic region of the flow, the velocity profile is shown to be of the following form, at least for the lower half of the velocity profile (Nikora and Smart, 1997):

$\frac{u}{U_{*}}=\frac{1}{\kappa} \ln \left(\frac{z}{Z_{o}}\right)$

This equation can be plotted in semi logarithmic form to provide values for both $Z_{0}$, and $U_{*}$. The procedure involves fitting a straight line by ordinary least squares regression to the profile and calculating values of $U_{*}$, and $Z_{\mathrm{o}}$ from the slope and intercept of the computed regression equation.

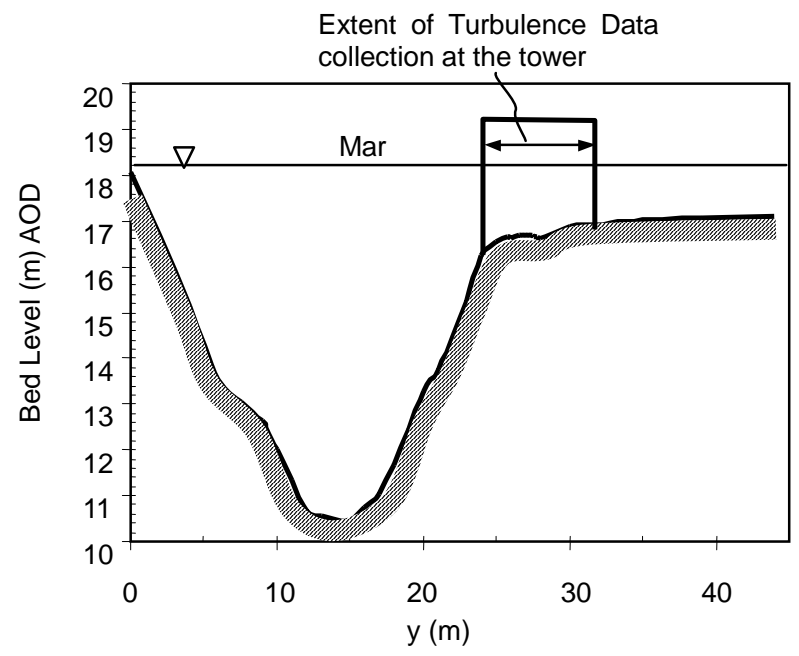

Figure 3. Turbulence data collection region at the tower. 
Table 1. Shear Velocity and Roughness Length Using Methods (a) to (c)

\begin{tabular}{|c|c|c|c|c|c|c|}
\hline Method & $\begin{array}{l}\text { Flood } \\
\text { Event }\end{array}$ & $\begin{array}{c}\text { Flood } \\
\text { Level } \\
(\mathrm{m})(\mathrm{AOD})\end{array}$ & $\begin{array}{c}\mathrm{Q} \\
\left(\mathrm{m}^{3} / \mathrm{s}\right)\end{array}$ & $\begin{array}{c}\mathrm{U}_{*} \\
(\mathrm{~m} / \mathrm{s})\end{array}$ & $\begin{array}{l}Z_{\mathrm{o}} \\
(\mathrm{m})\end{array}$ & $\begin{array}{l}\mathrm{k}_{\mathrm{s}} \\
(\mathrm{m})\end{array}$ \\
\hline \multirow[t]{2}{*}{ (a) } & $\begin{array}{c}\text { March } \\
2000\end{array}$ & 18.2 & 103 & 0.053 & - & - \\
\hline & $\begin{array}{l}\text { Oct. } \\
2000\end{array}$ & 17.8 & 91 & 0.103 & - & - \\
\hline \multirow[t]{2}{*}{ (b) } & $\begin{array}{c}\text { March } \\
2000\end{array}$ & 18.2 & 103 & $\begin{array}{r}0.083 \\
\sim 0.096\end{array}$ & $\begin{aligned} & 0.012 \\
\sim & 0.02\end{aligned}$ & $\begin{array}{r}0.18 \\
\sim 0.358\end{array}$ \\
\hline & $\begin{array}{l}\text { Oct. } \\
2000\end{array}$ & 17.8 & 91 & $\begin{aligned} & 0.063 \\
\sim & 0.07\end{aligned}$ & $\begin{array}{r}0.006 \\
\sim 0.009\end{array}$ & $\begin{array}{r}0.187 \\
\sim 0.237\end{array}$ \\
\hline \multirow[t]{2}{*}{ (c) } & $\begin{array}{c}\text { March } \\
2000\end{array}$ & 18.2 & 103 & $\begin{array}{r}0.059 \\
\sim 0.104\end{array}$ & - & $\begin{array}{r}0.068 \\
\sim 0.396\end{array}$ \\
\hline & $\begin{array}{l}\text { Oct. } \\
2000\end{array}$ & 17.8 & 91 & $\begin{array}{r}0.059 \\
\sim 0.068\end{array}$ & - & $\begin{array}{r}0.176 \\
\sim 0.205\end{array}$ \\
\hline
\end{tabular}

Note: The $\mathrm{k}_{\mathrm{s}}$ values are back calculated from $\mathrm{u} / \mathrm{U}_{*}=(1 / \kappa) \ln \left(\mathrm{z} / \mathrm{k}_{\mathrm{s}}\right)$ $+8.5$

(c) Shear velocity can also be determined from the measured Reynolds stress distribution

$\tau_{b}=-\left.\rho u^{\prime} w^{\prime}\right|_{z \approx 0}=\rho U_{*}^{2}$

where $\tau_{\mathrm{b}}$ is the shear stress at bed level, $-\rho u^{\prime} w^{\prime}$ is the Reynolds stress on the horizontal plane, and $\rho$ is the water density. The values of shear velocity and roughness length for the study reach of River Severn are calculated using methods (a) to (c) and the results are shown in Table 1.
There is a discrepancy between the calculated values of the shear velocities due to different methods. Method (a) provides an overall estimate of shear velocity. The result using this method depends on the water surface slope. Methods (b) and (c) provide a local estimation of shear velocity and as shown in Table 2 and their predictions are relatively close. Method (b) provides prediction for roughness length as well as shear velocity. The wide scatter in reported values of $Z_{0}$, as explained by Smart (1999), is due to the fact that the roughness length $Z_{0}$ does not solely depend on grain roughness (represented here by $d_{90}$ ). It also depends on the size of bed forms (the aggregation of sediment grains), bed load (rolling or saltating near-bed sediment layer), lateral velocity gradient, and stretching of the profile by acceleration or deceleration of the flow.

\section{Reynolds Shear Stress}

Reynolds stresses on the vertical and horizontal planes are calculated based on the turbulence measurements in the field. The vertical distribution of the horizontal shear $\left[\tau_{\mathrm{zx}}\right]$, at the tower interface region and for a flow of $103 \mathrm{~m}^{3} / \mathrm{s}$, is shown in Figure 4 . The variation of $\partial \tau_{\mathrm{zx}} / \partial \mathrm{z}$ is non-linear especially near the main channel $(\mathrm{y}=24.0 \mathrm{~m})$, and at the main channel/floodplain interface $(y=25.0$ $30.0 \mathrm{~m}$ ). This is due to existence of a lateral shear from the floodplain towards the main channel. Existence of secondary currents may also contribute to this nonlinear variation. Flow structure at $\mathrm{y}=24-25 \mathrm{~m}$ consists of a two-layer system at a river/floodplain interface highlighted by Shiono and Knight (1991) in the analysis of the large scale UK Flood Channel Facility laboratory data. Away from the main channel, this two-layer structure is less evident.

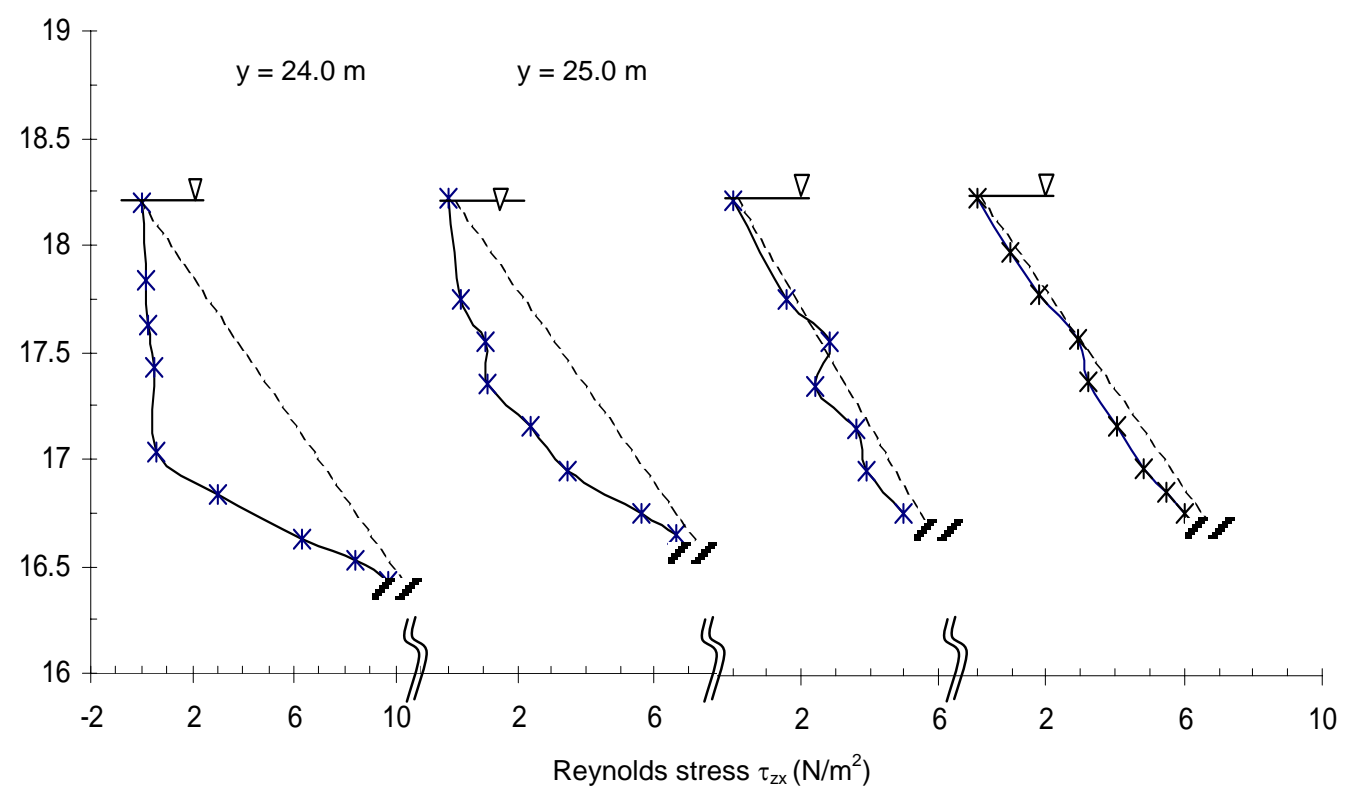

Figure 4. Reynolds shear stress from ADV. 


\section{Two Dimensional Flow Modeling}

A two-dimensional depth averaged model called River2D is used to investigate the accuracy with which the field measurements could be reproduced by the model.

The River2D model is a two-dimensional, depthaveraged finite element model developed by Steffler and Blackburn (2001) from the University of Alberta. It is intended for use on natural streams and rivers and has special features for accommodating supercritical /subcritical flow transitions and time varying wetting and drying. The river geometry is discretized using the key feature of the program to triangulate any arbitrary distribution of input nodes into a usable mesh. The aim of spatial discretization is to provide a high quality mesh that represents the boundary accurately while maintaining efficiency in solution convergence. A total number of 18000 elements were used to model the study reach. The mesh quality index was 0.3 and within the acceptable range of 0.15 to 0.5 . The mesh independence was achieved by comparing the final solutions for finer and coarser meshes. Figure 5 shows a depth-averaged plot of the velocity field obtained using the River-2D software. It shows that the flow, downstream of cross-section 1, expands from the main channel onto the floodplain where it travels in a skewed direction and joins the main channel before the cross-over [cross-section 3]. It also shows that the flow at the bend [cross-section 4] along the inner bank is faster than along the outer bank. An area of increased velocity is also apparent at the interface between the main channel and the floodplain at cross-section 5. These flow features, shown in Figure 5, indicate the model potential to reproduce the flow pattern in meandering compound rivers during overbank flows.

The model was calibrated using the field velocity data obtained during flood March 2000 and Figure 6 shows the results. A $\mathrm{k}_{\mathrm{s}}$ value of $0.4 \mathrm{~m}$ (for both the main channel and the floodplain) appears to give a better prediction for the measured field velocities. $\mathrm{A}_{\mathrm{s}}$ value of $0.4 \mathrm{~m}$ seems reasonable and it is roughly equivalent to a Manning coefficient of $n=0.033$. Although one would expect different values of roughness for the main channel and the floodplain to be more realistic especially during different seasons throughout the year, but an effort to use a combination of different values in this study showed very little change in the overall velocity predictions. This may be due to the fact that the modeling approach is depth-averaged so the effects of variations in boundary roughness is also depth-averaged and less pronounced.

\section{Three Dimensional Flow Modeling}

A fully 3-D computer model, CFX, has been used to model the flow in the study reach. Two numerical grids with different node densities are constructed for each river model after a suitable structure of blocks has been implemented to describe the channel morphology. However, the number of elements is deliberately kept low as the complexity of the geometry will generate additional difficulties that are likely to require a higher processing power. In addition, small spurious elements might also be created, as the grid becomes finer. They are known to be a source of difficulty, especially in the numerical treatment of turbulence terms at the walls, which could cancel out the benefits of the finer resolution by impeding convergence.

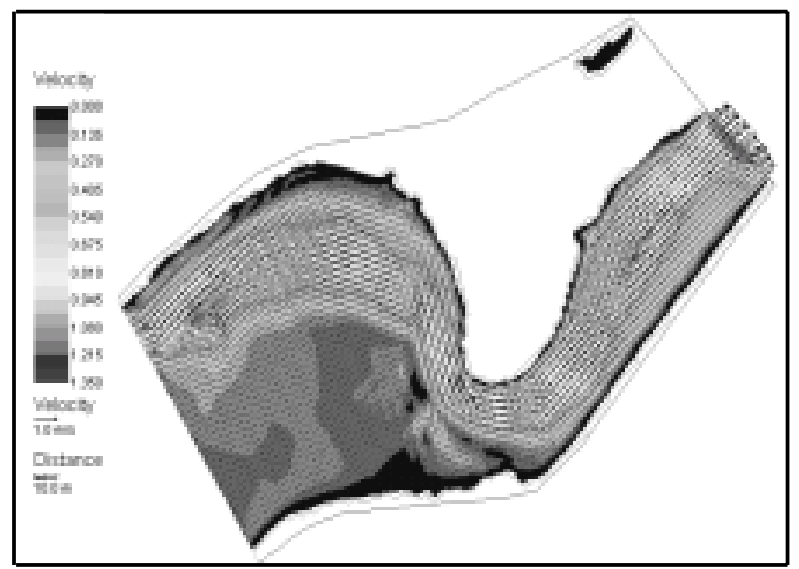

Figure 5. Velocity magnitudes and vectors for a flood discharge of $\mathrm{Q}=103 \mathrm{~m}^{3} / \mathrm{s}$ in the study reach of River Severn (UK).

The process of refining the grid to assess the level of mesh dependence assumes advance knowledge where grid enhancement would be most needed, and therefore which are the problematic flow features likely to be poorly resolved. In the present case however, it is anticipated that one of the problematic features will be the sharp gradients of velocities, at the walls and cross-over. The first grid constructed for the Severn is made of 97,732 elements. It has 10 elements positioned across the channel and 14 over the vertical, both with a growth ratio of 1.5. There are only 4 elements over the vertical in the flood plain area because the water depth is about $1.5 \mathrm{~m}$. The mean resolution in the domain is therefore of $0.6 \mathrm{~m}$ on the vertical and $1.8 \mathrm{~m}$ laterally and $2.0 \mathrm{~m}$ in the channel longitudinal direction. The first element is typically located at a distance of $0.77 \mathrm{~m}$ from the wall in the vertical direction and $0.80 \mathrm{~m}$ in the lateral direction at the bottom.

Further refinement is conducted to create a second grid made of 183,138 elements. This is done by the enhancement of the lateral and vertical distributions so that 17 nodes are created on the vertical and 15 laterally in the main channel, and 5 elements vertically on the flood plain. This represents an averaged resolution of $0.5 \mathrm{~m}$ in the vertical direction, $1.2 \mathrm{~m}$ in the lateral direction and about 1.6 in the longitudinal direction. These two grids are named CFX S-1 and CFX S-2 respectively. 

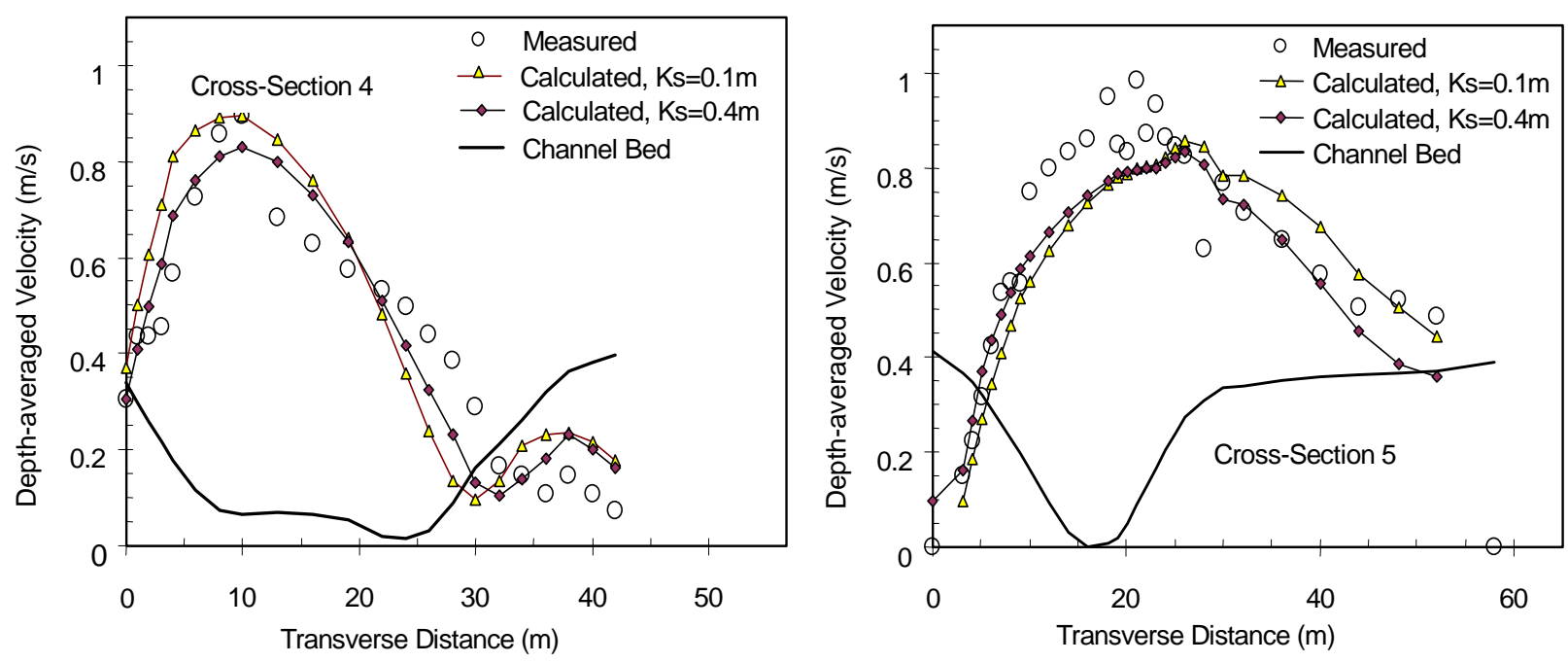

Figure 6. Depth-averaged field velocity data and predicted values.

Mesh enhancement is difficult to conduct in the case of the River Severn because any cross-sectional refinement entails a costly refinement in the longitudinal direction due to the block arrangement. This difficulty stems from the reach layout, in which the main channel forms an "S" shape that contains the flood plain, and therefore cannot be described by a simple structure of blocks running parallel to the channel. Instead the multiblock description of the channels leads to "nested" elements on the flood plain. In addition to the above difficulty, the cross-sectional shape of the Severn also provides an additional complication. Its V-shape means that it is difficult to obtain a fairly regular resolution over the channel width with the depth, especially in places close to the bed where the section is particularly narrow and where bottom and side walls intersect.

A comparison between the CFX model and the velocity data collected at cross-section 4 in indicates that model and data display similar velocity fields, see Figures 7 , and 8. A fast flow in the region of $0.75-0.80 \mathrm{~m} / \mathrm{s}$ is the visible in the left upper half of the channel on both series of plots, while a velocity core of about $0.75 \mathrm{~m} / \mathrm{s}$ is running along the left bank. In the data this core is slightly inclined to the left as predicted in the CFX model where it can be seen to "lean" against the bank slope due to the flood plain flow lateral shear. In the lower right part of the channel the measured velocities reach $0.50 \mathrm{~m} / \mathrm{s}$ as predicted by the model, while they are reduced to $0.40 \mathrm{~m} / \mathrm{s}$, against $0.30 \mathrm{~m} / \mathrm{s}$ for CFX, in the upper part. For the recorded data between cross-sections 3 and 4 similar comments apply when considering the predicted flow at sections 3 and 4 in the model. This suggests that the physics of the flow is well captured by the model around the meander.
In Figure 9, a more objective analysis compares some of the velocities measured over the water column depth in the region of cross-sections 3 and 4 with the model's predictions. From these comparisons it is clear that there exists larger discrepancies than previously expected between data and predictions at given locations. The order of the difference is about 20 to $30 \%$. However, the shape of the velocity profiles is also reasonably reproduced at most locations and a significant part of the difference is at the walls. In general CFX under-predicts the velocity field at most locations.

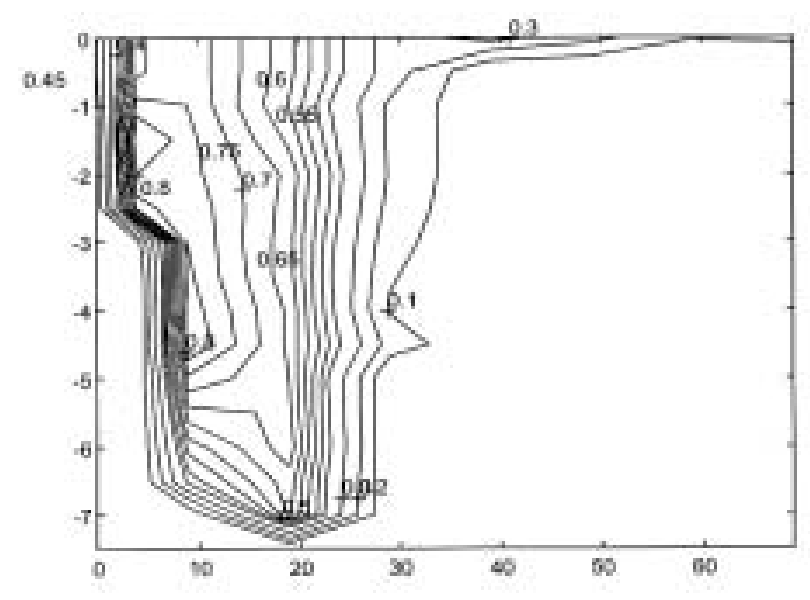

Figure 7(a). Measured velocity profile between cross-sections 3, 4 in River Severn (m/s; Dec. 2000). 

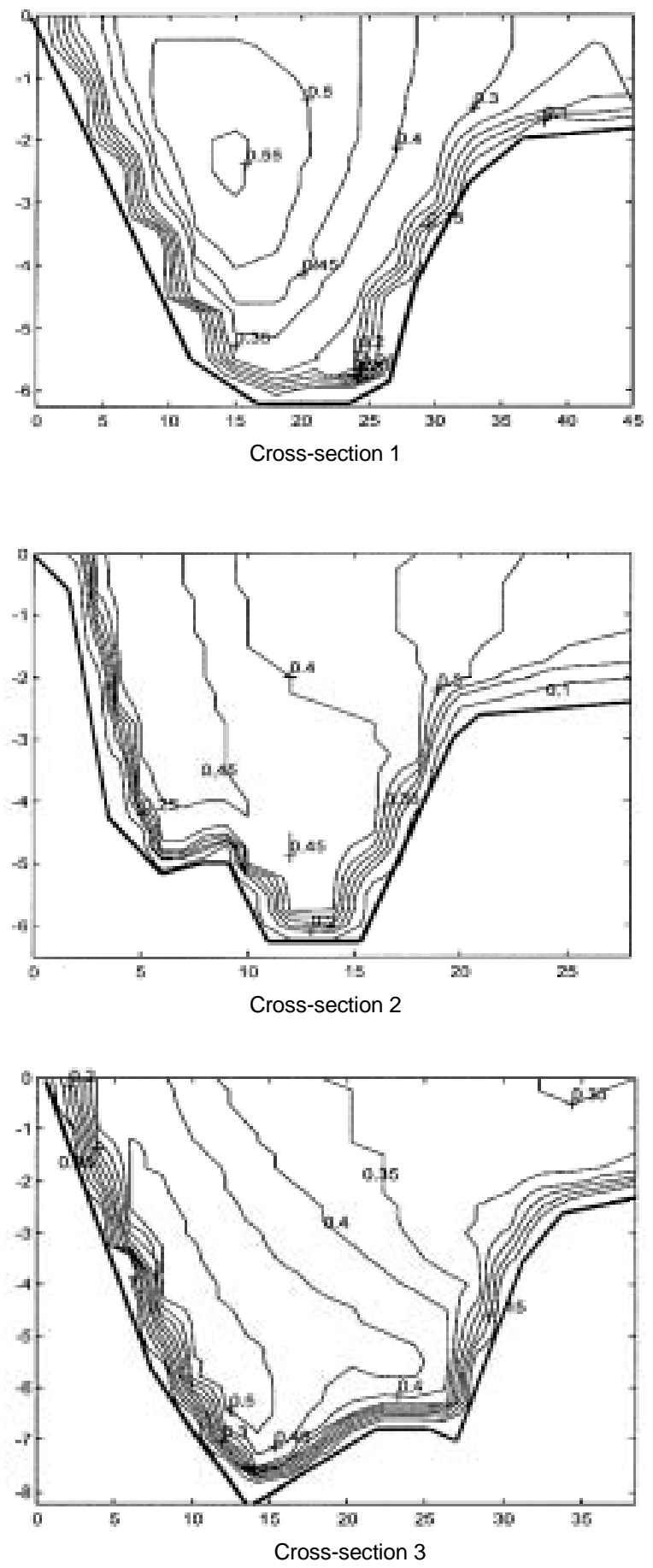

Figure 7(b). River Severn CFX velocity profile $(\mathrm{m} / \mathrm{s})$ at cross-sections 1,2 and $3\left(k_{s}=0.100 \mathrm{~m}\right.$, grid CFX S- $1, k-\varepsilon$ model).

Part of the difference between predictions and observations could be explained by the fact that one is attempting to compare a simulation for a steady flow with a $100-\mathrm{m}^{3} / \mathrm{s}$ discharge with different unsteady flood flows with approximate, fluctuating discharges. It could indeed be stemming from an erroneous prediction of the discharges from the field data, as the discharge values were determined by integration of the velocity measurements. An attempt is made to try and resolve part of this uncertainty by running the model for a discharge of $120 \mathrm{~m}^{3} / \mathrm{s}$. The results with CFX are better and the match between the velocity profiles visibly enhanced at cross-section 4 . However improving the velocity at section 4 results in a slightly faster flow at cross-section 3 , and raises the question of the model's calibration for such a flow (notably the pressure on the lid). If the test clearly suggests that errors in the measured discharge could account for the difference between model and data, it does not imply that the model is faultless. At best it highlights how difficult it is to assess a three-dimensional model quantitatively with only restricted data such as the water surface profile, approximate discharge values and a few velocity measurements in such a complex geometry.

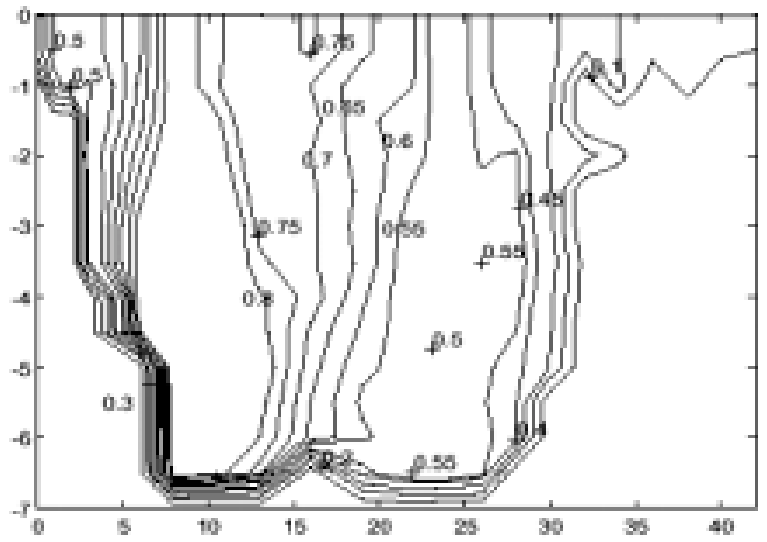

Figure 8(a). Measured velocity profile at cross-section 4 in River Severn (m/s; Nov. 2000).

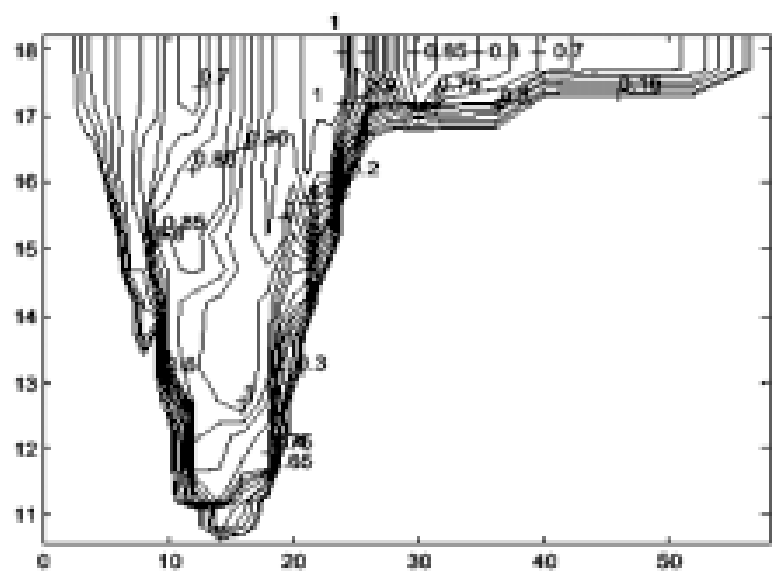

Figure 8(b). Measured velocity profile at Cross-section 5 in River Severn (m/s; Nov. 2000). 

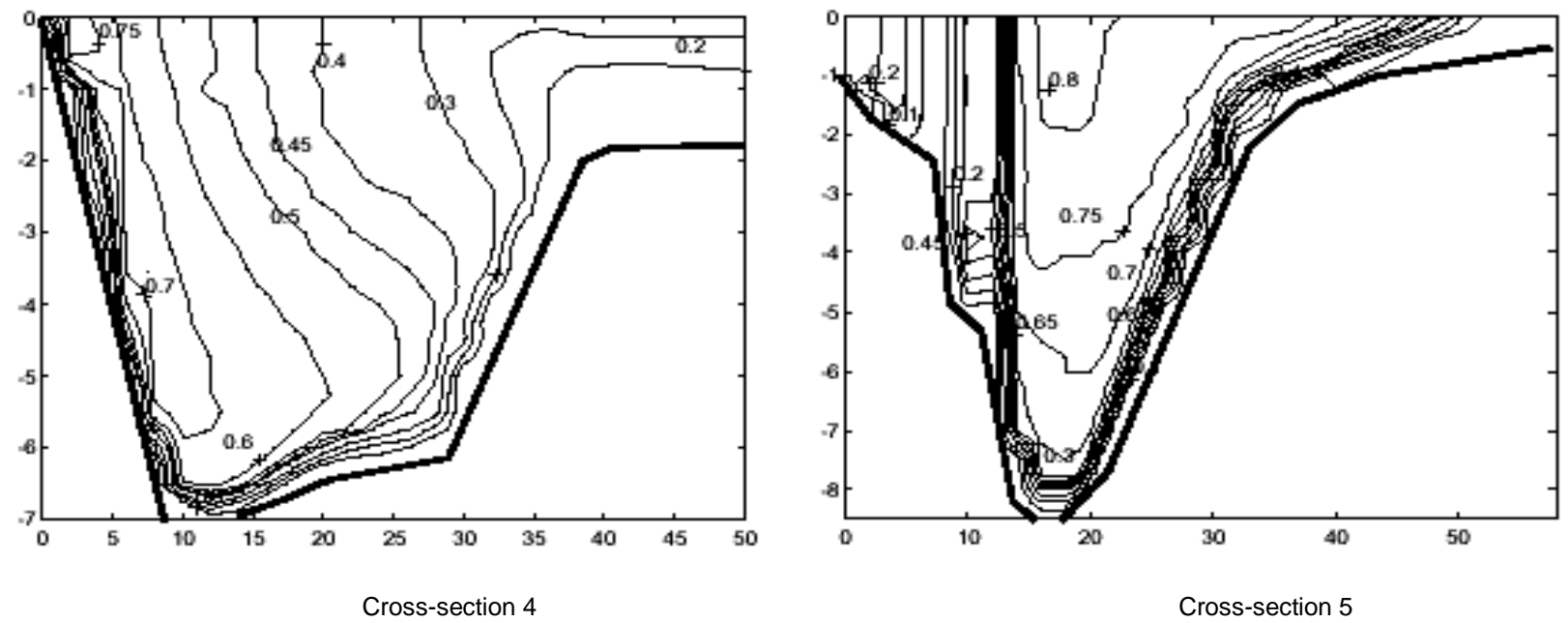

Figure 8(c). River Severn CFX velocity profile at cross-sections 4 and 5 ( $k_{s}=0.100 \mathrm{~m}$, Grid CFX S-1, $k$ - $\varepsilon$ model).

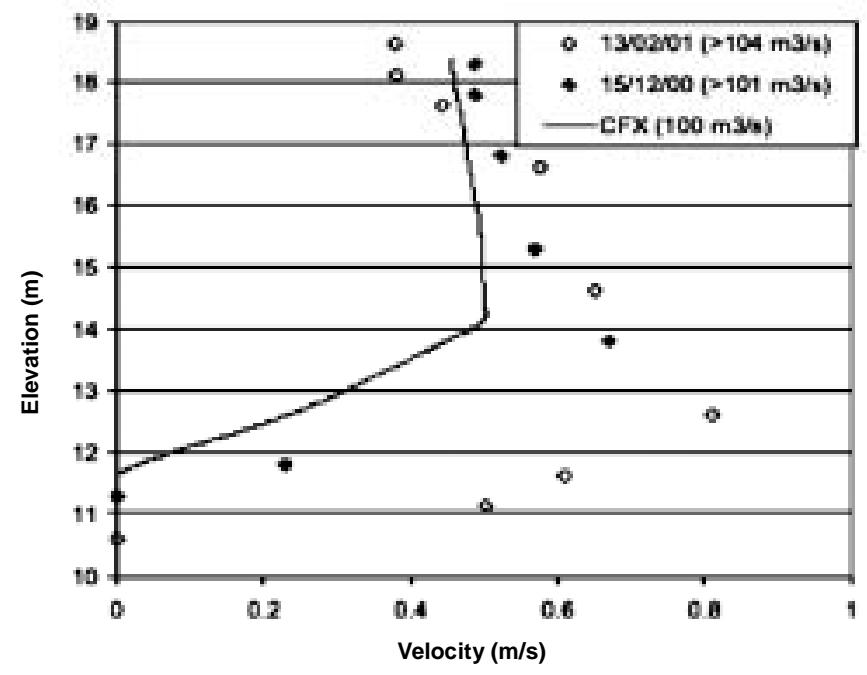

At $9.00 \mathrm{~m}$ from the Left Bank

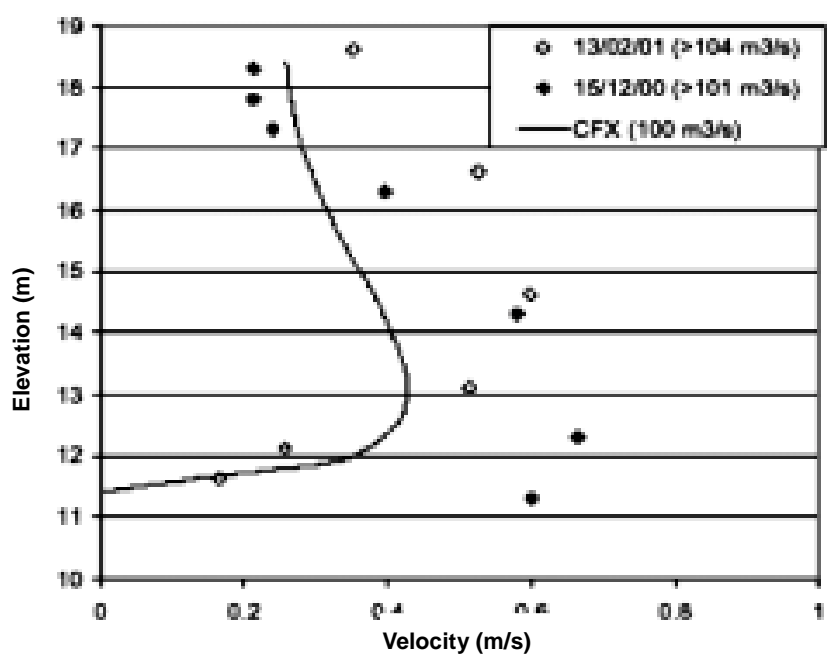

At $19.00 \mathrm{~m}$ from the Left Bank

Figure 9(a). Comparison between field data and River Severn CFX model predictions at cross-Section 4. 

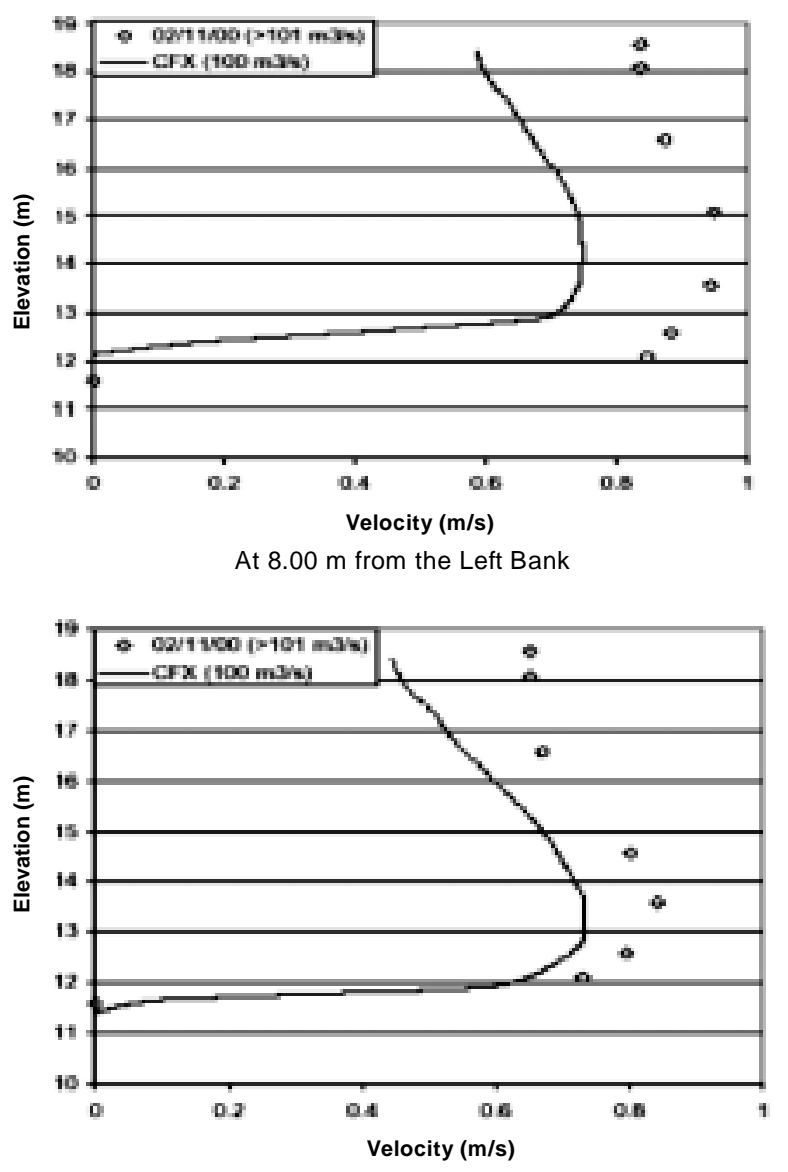

At $12.00 \mathrm{~m}$ from the Left Bank

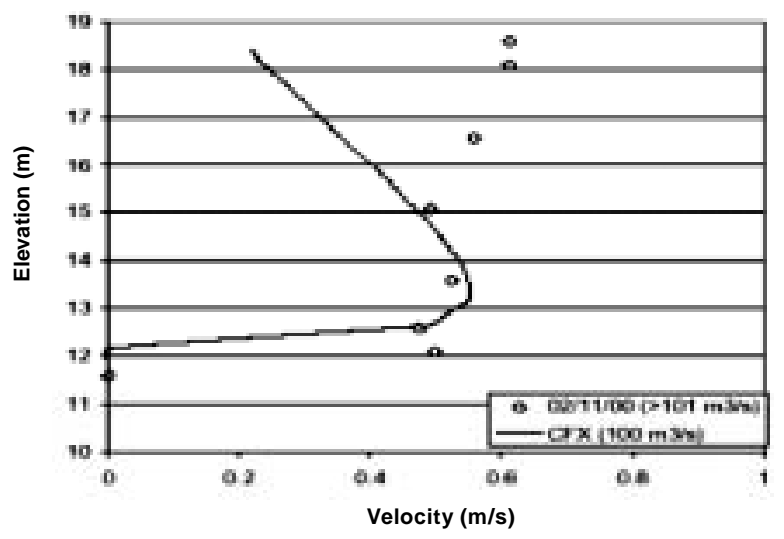

At $22.00 \mathrm{~m}$ from the Left Bank

Figure 9(b). Comparison between field data and River Severn CFX model predictions at cross-section 5.

\section{Concluding Remarks}

Based on the field measurements of velocity, turbulence, and flow modeling in a study reach of the River Severn during overbank flows the conclusions are:

- The shear velocity and roughness length for the River
Severn were calculated using three different methods (a) to (c), see Table 1. Method (a) provides a global estimate of shear velocity where methods (b) and (c) provide a local estimation of shear velocity.

- The vertical distribution of measured horizontal turbulent shear $\tau_{\mathrm{zx}}$ shows that the variation of $\partial \tau_{\mathrm{zx}} / \partial \mathrm{z}$ is not linear, especially in the main channel and at the main channel/floodplain interface. This is due to the existence of both lateral shear and secondary currents.

- The variation of lateral turbulent shear $\tau_{\mathrm{yx}}$ shows that for a given value of $z$, the $\tau_{\mathrm{yx}}$ values reach a maximum at the main channel/floodplain interface.

- Reasonable predictions of depth-averaged velocities are obtained using a $\mathrm{k}_{\mathrm{s}}$ value of $0.4 \mathrm{~m}(\mathrm{n}=0.033)$

- With progress in modeling techniques and fast PCs, the use of 2D models would appear to have potential in modeling moderate lengths of river reach. In many cases this can be achieved almost as easily and economically as using 1-D models.

- One of the most challenging problems with numerical modeling of flow through a natural river reaches stems from the complexity of the geometry and its disruptive effects on the numerical solution. In this context the use of a structured grid (although multi-block) in CFX has proved quite difficult and entailed a lot of manual mending and smoothing of the boundaries.

- The use of a proper spatial discretization is essential to a good representation of the flow features in regions of sharp gradients of the variables. In the case of overbank flows, the resolution has to be enhanced at the flow interface between the flood plain and the main channel and at the banks. For similar reasons it is desirable to have fine grid spacing at the walls in order to capture the velocity profile near the boundary.

- The roughness height and $k_{s}$ values computed using a measured logarithmic velocity profile are higher compared to the values usually required for 3-D models e.g CFX or Telemac 3D for modeling purposes. The reason for such a difference is that the $k_{s}$ values calculated using a logarithmic velocity profiles does include all the losses i.e. due to friction, bend, converging or diverging flow, etc, hence resulting in a higher values where as the $k_{s}$ used in 3-D models accounts only for skin friction losses.

Acknowledgments. This study was supported by the financial support of the Engineering and Physical Sciences Research Council (EPSRC) under Grant No.GR/L95038. The authors gratefully acknowledge the EPSRC financial support. The 3-D modeling results presented here were carried out by Dr. H. Morvan as a part of his Ph.D. study at the University of Glasgow. The authors would like to thank Prof. P. A. Carling, Dr Z. Cao, and Mr. M. J. Holland for their invaluable contributions to this research.

\section{References}

Babaeyan-Koopaei, K., Ervine, D.A., Carling, P.A. and Cao, Z. (2002). Velocity and turbulence measurements for two over- 
bank flow events in the River Severn, in Proc. ASCE, J. Hydraul. Eng., 128(10), pp. 891-900, October 2002.

Carling, P.A., Cao, Z., Ervine, D.A. and Babaeyan-Koopaei, K. (2002). Turbulent flow across a natural compound river channel. J. Water Resour. Res. (Paper No. 10.1029/2001 WR 00902, Dec. 2002).

Knight, D.W. and Shiono, K. (1990). Turbulence measurements in a shear layer region of a compound channel. J. Hydraul. Res., 28(2), 175-196.

Morvan, H. (2001). Three dimensional modeling of rivers, Ph.D. Thesis, University of Glasgow, Glasgow, UK.

Morvan, H., Pender, G., Wright, N.G. and Ervine, D.A. (2002). Three dimensional hydrodynamics of meandering compound flows, in Proc. ASCE, J. Hydraul. Eng., 128(7), 674-682.

Nezu, I. and Nakagawa, H. (1993). Turbulence in open-channel flows, Balkema, Rotterdam, Netherlands.

Nikora, V.I. and Smart, G.M. (1997). Turbulence characteristics of New Zealand gravel bed rivers. J. Hydraul. Eng., 123(9), 764-773.

Nikora, V.I. and Goring, D.G. (1998). ADV measurements of turbulence: can we improve their interpretation? J. Hydraul. Eng., 124(6), 630-634.

Shiono, K. and Knight, D.W. (1991). Turbulent open channel flows with variable depth across the channel. J. Fluid Mech., 222, 617-646.

Smart, G.M. (1999). Turbulent velocity profiles and boundary shear in gravel bed rivers. J. Hydraul. Eng., 125(2), 106-116.

Steffler, P. and Blackburn, J. (2001). River2D: Two-Dimensional Depth Averaged Model of River Hydrodynamics and Fish Habitat, University of Alberta, Edmonton, Alberta, Canada. 